Helgoländer wiss. Meeresunters. 24, 264-275 (1973)

\title{
Direct observations of resource sharing in coral reef fish
}

\author{
C. L. SMITH \& J. C. TyLeR \\ Department of Icbtbyology and Lerner Marine Laboratory, \\ The American Musetum of Natural History; \\ New York, USA
}

\begin{abstract}
EXTRAIT: Observations directes sur la stabilité et le partage des ressources dans les communautés de poissons habitant les récifs coralliens. La complexité structurale des récifs coralliens rend difficile le recensement des poissons qui y vivent, alors que cependant ces rassemblements extrêmement complexes offrent une excellente occasion d'étudier les mécanismes aboutissant au développement et au maintien d'une communauté animale hautement diversifiée. Au cours des operations «Tektite» et «FLARE» les auteurs ont procédé à une observation directe de populations de poissons sur de petits récifs coralliens, en utilisant des appareils «Rebreathe» et SCUBA à circuit ouvert. Une troisième station fut équipée d'un appareil de télévision sousmarin à circuit fermé, permettant d'observer une population de poissons pendant une durée prolongée; un tel dispositif ne trouble aucunement le comportement des poissons observés, mais n'est utilisable que pour des espèces d'assez grande taille et ne se cachant pas dans les anfractuoistés des récifs. La télévision permet une observation de durée illimitée et constitue le seul moyen de recenser les gran des espèces nomadiques, que l'approche d'un plongeur met en fuite. Pour les petites espèces vivant cachées, le recensement et les autres observations in situ ne peuvent être effectués, pendant un temps suffisant, qu'à partir d'un habitacle sousmarin. Ainsi peuvent être rassemblées des données permettant la discrimination entre espèces transitantes, visiteuses ou résidentes; l'évaluation du taux de remplacement; la situation des abris et des terrains de chasse; la stabilité des groupes et essaims; les cycles d'activité; la diversité des réactions interspécifiques aboutissant à l'organisation et à la stabilité des communautés. L'observation n'entraînant aucune destruction peut être poursuivie pendant une longue durée.
\end{abstract}

\section{INTRODUCTION}

Recently, many ecologists have focused their attention on the general problem of the origin and maintenance of diversity of species in natural communities. The fundamental question of why there are so many species can only be attacked by a consideration of how energy and materials flow through the community and how the available resources are shared by the organisms comprising the community. When sufficient data are available mathematical models can be constructed that reflect the pathways and cycles of energy and materials within the community. These models can be tested and refined until they are accurate enough to be used for predicting the 
results of stresses such as overfishing, the introduction of new species, and natural and man-made environmental changes. Models also indicate where critical data are lacking and serve to direct further research.

Models, however, can only be as good as the assumptions and data on which they are based. For many, indeed most, tropical marine species, we still have much to learn. This is especially true of mobile animals like fishes. Basic natural history data are rarely complete and our information about species interactions is sketchy indeed. When it comes to community structure and stability we are just beginning to ask the right kinds of questions.

The data that we so desperately need must come from three sources: (1) field samples taken by nets, dredges, poison stations, etc., (2) controlled laboratory experiments performed on captive individuals, and (3) direct observations of the organisms in their wild state. For aquatic organisms the direct observations have been limited, awaiting the development of an appropriate technology, which is now available.

Like all other types of data, field observations have to be repeated a sufficient number of times to establish statistical limits and to be certain that they do not represent some anomalous condition. They have to be interpreted in accordance with rigorous, logical procedures just like any other observational or experimental data. Nevertheless, it is often more efficient to make direct observations simply because such observations sometimes obviate the need for tedious elimination of alternative hypotheses. We can, for example, infer something about an animal's food habits from its anatomy but to confirm this inference requires many samples and stomach analyses, whereas direct observations of feeding behavior are often possible and give us immediate meaningful data.

Because observations do not yield specimens, much greater care must be devoted to identification of the species involved. Frequently it is necessary to make collections to confirm observations, and the use of photography to support observations is important, especially for events that occur too rapidly for the human eye to follow.

Direct visual observations are restricted to reasonably clear water; visibility of at least a few decimeters is required and more is desirable for most purposes. Low temperatures also multiply the difficulty of spending sufficient time in the water to obtain meaningful information. For nocturnal observations and in those regions where light levels are low, artificial illumination may be necessary and this can introduce a bias that is difficult to evaluate. Moreover, the presence of the observer is always a disturbing influence. Nevertheless, direct, in situ observations yield data that are far closer to the undisturbed state than either laboratory (aquarium observations) or indirect sampling methods.

Many significant observations have been made from the surface with and without the aid of glass bottom boxes but modern technology has now provided refined equipment that improves accuracy and efficiency. Direct observations can be made from submerged, surface-accessible chambers, from submersible vehicles, by diving, and by remote underwater television. Most diving today is done with simple skin diving equipment (mask and snorkle) or by surface-supplied or selfcontained underwater breathing apparatus (SCUBA). 
Conventional open-circuit SCUBA has the advantages of cheapness, convenience and safety, but the disadvantage of giving off bubbles that alarm some fishes and affect their behavior. The use of open-circuit gear also limits diving time because a single tank of air lasts less than one hour at most working depths, in proportion to depth and several other factors. Surface-supplied diving gear (Hookah) can extend time underwater and in some circumstances is safer, but it is not as flexible and does not allow the diver as much freedom of movement. Closed-circuit or rebreather gear is good for 8 to 10 hours without recharging, independent of depth but depending on the diver and his activities. Rebreathers are expensive and not in general use at this time but will be more widely used in the near future.

Whether a diver uses open circuit or rebreather gear, there is always the problem of decompression when divers stay at depth for long periods or make repeated dives during a limited period. For extensive underwater observation, saturated diving from underwater habitats, where divers can remain at pressure for longer periods, is necessary to reduce the time spent in decompression to a reasonable percentage of the total working time.

For most diving scientists depths are limited to less than fifty meters. Rebreather gear is designed for working at depths in excess of 350 meters but the problems of decompression, the use of gas mixtures other than compressed air to avoid nitrogen narcosis and oxygen poisoning, and maintenance of the equipment requires so many support personnel that its use at great depths will, for the forseeable future, be limited to large organizations and special projects. The individual scientist working with one or two assistants will continue to use open-circuit SCUBA and to be restricted to the upper $50 \mathrm{~m}$ of the littoral and epipelagic zones. There is still much to be learned by using simple mask and snorkle gear in shallow water.

This paper will examine some of the types of data needed for analyses of the functioning of coral reef fish communities that can best be obtained by direct observations. Our discussion will focus on three studies we have personally carried out: a small isolated patch reef studied during a two week mission in. Tektite II using closed-circuit SCUBA (SMrrh \& TrLen 1972), a small coral stack in a large reef area censused during a two and one-half day mission in project FLARE, using open-circuit SCUBA, and a small section of the Bahama bank scanned by a permanently mounted sea-floor television censused intermittently over a one and one-half year period (SMITH \& TYLER in press).

Although the Underwater Television (UTV) image is transmitted electronically to a remote receiver, we consider this direct observation because the action is seen as it occurs. UT' $V$ can be portable or it can be permanently emplaced on the bottom for long periods of time, but it suffers from two disadvantages - it is not as mobile as a diver and its resolution is not good enough for some purposes. On the other hand, it gives unlimited viewing time and once in place causes virtually no disturbance to the organisms being observed and can be used with a video tape recorder for permanent documentation of behavioral and other phenomena. 


\section{RESULTS}

\section{Census data}

The first step in any community analysis is a census of the species present and their relative and absolute density. Census data are rarely complete and usually depend on sampling techniques or on some indirect methods such as mark and recapture experiments. In coral reef environments tag and recapture methods are not applicable to small fishes and the only effective sampling methods for fishes involves the use of a poison to stun or to kill the fishes which are then picked up by divers. SMITH (1973) has discussed the effectiveness rotenone stations and concluded that 2 or 3 applications of rotenone, a few hours apart will effectively kill about $85-95 \%$ of all the fishes present. Unfortunately, this approach has the major disadvantage that it kills the fish and thus precludes monitoring the population over a period of time. The only non-destructive way to census populations is by means of visual counts either along transect lines (Brock 1954, BARDACH 1959) or in patches of habitat that are small enough to be studied as complete units. For our studies we have chosen the latter. Our Tektite study reef was an isolated patch reef, roughly triangular and about $3 \mathrm{~m}$ on each side with an estimated volume of $5.3 \mathrm{~m}^{3}$. Our FLARE study concentrated on a hemispherical coral head about $1.5 \mathrm{~m}$ in diameter by $1.5 \mathrm{~m}$ high. Solitary and low density species were plotted on a base map; schooling and more mobile forms were merely tallied on underwater slates. Census results are given in Table 1.

Table 1

Census data from three coral reef habitats

\begin{tabular}{lccc|}
\hline & Tektite & FLARE & UTV \\
\hline Total numbers of species & 75 & 42 & 89 \\
Residents & 53 & 14 & 51 \\
Transients and visitors & 22 & 28 & 38 \\
\hline
\end{tabular}

Visual counts suffer from two difficulties. Fishes that are free living and in constant motion are difficult to count accurately and the only solution we have found is for two investigators to repeat the counts until consistent results are obtained. The estimating of numbers of fish in schools requires some practice. Sometimes one can get an estimate of the density of the fishes so that the number in the school can be computed from its volume.

The second problem encountered with coral reef fishes is that a number of reef fishes apparently are so secretive that they cannot be observed by divers. Courtenay (1967) and Böhlke \& Chaplin (1968) have commented on some of these. At the end of our two-week Tektite study we had observed 68 species but still 2 rotenone samples yielded 7 other species that we had never seen, despite an effort to look into all holes and probe all algae clumps. Six other species were more abundant in the rotenone collections than in our counts, indicating that some individuals were better hidden than others. On the other hand, we observed 22 species that were not collected 
by rotenone, mostly transient and visitors, and 16 others were seen in larger numbers than appeared in the rotenone samples.

The underwater television unit was originally designed by the University of Miami for bioacoustics research and had also been used for studies of fish behavior. The camera unit was controlled from a shore laboratory, where pan and tilt, focus, zoom lens, and iris controls were at the observer's fingertips. For census work we systematically swept the field, recording all fishes in each $30^{\circ}$ sector of the field of view which included open sand and grass flats and natural and artificial reefs. The volume swept was approximately $1420 \mathrm{~m}^{3}$.

The resolution of the underwater television did not permit reliable counts of fishes smaller than $50 \mathrm{~mm}$ unless they came close to the camera. The strong point of the UTV is that it causes no disturbances and can therefore be used for larger fishes that flee at the first approach of a diver. Unfortunately these fishes are mostly wanderers, either nomads or with very large home ranges, hence the UTV cannor be used as a measure of their density but only as an indication of their presence or absence during a particular period. UTV does give a good indication of the density of certain species that have limited home ranges and are conspicuously active during daylight hours.

All census techniques, including direct observation, are subject to bias of one sort or another and only by comparing the results of independent approaches can we become aware of the existence of this bias. One of the most important applications of direct observations is in evaluating the operation of other gear such as traps and trawls (Hrgh \& BEARDSLEY 1971, MuNRo et al. 1971).

\section{Population dynamics}

Perhaps because of the lack of commercial importance of most reef fishes, very little has been done with basic population dynamics. Data on natality, mortality, growth, recruitment, and immigration rates have not yet been forthcoming. Many of the reef species are too small and secretive to tag, hence data on movement and migrations will have to be obtained by the tedious but direct process of watching closely enough to learn to recognize individuals and then following the fish to see how large their home ranges are and to see how long they remain in a single patch of habitat. Such data also help us to define the limits of the habitat patches. At our Tektite reef we found that fishes moved freely between the main reef and some coral colonies that were less than two meters away. Further, many species left the reef to forage over sand flats and we conclude that the habitat includes the nearby colonies and the surrounding sand flats as well as the actual reef structure. Nevertheless, we learned to recognize resident individuals and verified the impression that the community is a stable functioning unit, at least during periods of two weeks and undoubtedly much longer.

Our Tektite and UTV observations have also led us to the conclusion that the relationships between resident, visitors and transients is a complex aspect of community function. There is a gradation in size of home ranges. Some residents have home ranges that are smaller than the patch under consideration, others have larger 
home ranges and the fraction of their time spent in the area is inversely proportional to the size of the home range. The contribution of nomadic species to the economy of a small patch of habitat is related to their abundance. An abundant species will be present nearly all of the time even though no resident individuals make their home there.

Transients sometimes have the indirect effect on the residents of an area of causing them to expend energy in defensive behavior even though the transient merely passes through and makes no actual attack.

As the observer learns to recognize individual fishes, it becomes possible to log the arrival and departure of new individuals as immigrants or juvenile recruits. This then is a direct measure of turnover rates but it will only be meaningful when longterm studies can be carried out.

\section{Natural history and general behavior studies}

In order to gain a real understanding of the role each species plays in the environment it is essential to know just what each species does, from the time it first enters the community, through its reproductive period and finally how it dies or leaves the community.

Coral reef fishes have varied and often complex reproductive mechanisms. Some species spawn readily in an artificial environment and can be studied in the laboratory, but with such studies one can seldom be sure how much the artificial habitat may be distorting the behavior patterns. Therefore, even for species that do spawn in captivity, it is necessary to verify laboratory observations with in situ studies. For species that do not reproduce in captivity, diver's observations are the only way to study reproductive behavior.

The life histories of few coral reef fishes have been studied even in a general way and we certainly have no real understanding of how the basic behavior patterns are modified in the presence of other species. SMITH \& TyLER (in press) have postulated that as new species enter a habitat they modify the life styles of the species that are already present and force them to use their special adaptations for feeding, defense, or otherwise utilizing a particular niche. Thus, selection favors ever more precise specialization, which leads to greater resource sharing and increased species diversity. Verification of this line of reasoning, it is apparent, can only come from a vast number of field observations of fishes in well-censused communities. Most of the interactions, we suspect, will be exceedingly subtle and hard to recognize but some will be clearcut. The only way to find these will be direct observations of natural and experimentally modified wild communities. Observations on captive specimens are of little significance in this work although aquarium experiments can be used to confirm and elaborate field observations.

\section{Space resource sharing}

Census data alone give information about the standing crop of organisms present but reveal nothing about how the space is shared. The details of the distribution of 
organisms can only be determined by in situ studies of the individuals present. Elsewhere we have discussed space sharing of the fishes of the Tektite reef (SMITH \& TYLER 1972). Essential aspects of space sharing include; the status of each species as resident, transient, or visitor; the size and location of hunting areas and home or shelter sites; and activity cycles including time spent in hunting, resting and other activities such as being cleaned by parasite pickers, defending territories, and building and repair of burrows. Because our study was conducted in October, when there was little or no reproductive activity, we were unable to consider the problem of competition for nesting and courtship areas.

At the Tektite reef, home ranges of resident fishes varied in size from a few cubic centimeters to many cubic meters and some transient species appeared to have no particular home ranges. There is a general correlation with size - small fishes tended to have very small home ranges - but this is not universally true. Predaceous and herbivorous fishes (groupers and surgeon fishes) tended to have large hunting areas whereas plankton croppers (Pomacentridae) and sand-sifting gobies have small home ranges.

Homes or shelter sites are an essential aspect of defensive behavior and critical to the survival of the species. In general, home sites are selected that permit the fish to take advantage of their camouflage. Thus, gobies that live in black sponges tend to be black in color, sand dwellers tend to be hyaline, and fishes that live in algae tend to match their background. At the Tektite reef we interpreted schooling as a type of resting behavior.

Well-defined activity cycles are the rule among coral reef fishes. With the exception of some groupers, most fishes appeared to be either diurnal or nocturnal; we did not find any forms that were clearly crepuscular. Hobson (1968), Collette \& TAlbot (1972), Livingston (1971) and Starck \& Davis (1966) have all used direct observation techniques to study activity cycles of marine fishes. Collet'te \& TAlbot (1972) concentrated particularly on day-night changeover patterns. These are the critical periods when the diurnal species retire to their shelter sites and nocturnal species become active, and vice-versa. Perhaps at no other time of day is the integrated nature of the community so well-illustrated as during these changeover periods.

For most fishes the day seemed to be divided into resting and feeding cycles with some time when they appeared to be doing neither. Some species spend much time being groomed by cleaning fish or shrimp and others devote a great deal of effort to caring for their burrows. During parts of the year a large fraction of the fishes' time will be devoted to reproductive activities.

In our Tektite study we occasionally experienced difficulty in determining whether a species was nocturnal or diurnal simply because when it was seen to be hovering motionless near the reef structure, we could not decide whether it was resting or hunting for prey.

Our present opinion is that most fishes avoid interspecific competition by specializations of form and behavior that make it possible to subdivide the volume available without continual conflict with other species, but that intraspecific competition limits the population of each species to the carrying capacity of the habitat. 


\section{Food resource sharing}

Food studies on coral reef fishes are not extensive; Hiatt \& STRASburg (1960) and RANDALL (1967) are the chief sources on the subject. Fishes are notably opportunistic feeders - otherwise angling with metal and plastic lures would not be so successful - and it is our contention that how and where a fish feeds are more important than what it eats, at least in the light of our current knowledge. There is scant evidence that food ever is limited in quantity in coral reef areas and our present hypothesis is that the potential for competition with other species has had more of a selective effect in the evolution of feeding specializations than any actual shortage of food.

RANDALL (1965) screened certain areas of the reef in order to evaluate the effect of grazing herbivorous fishes on plants adjacent to reefs. (Many authors have commented on the sparseness of plants within 10 meters of a reef structure and this region is now informally known as the "Randall zone".) Working from Tektite II, EARLE (1972) was able to extend these studies and to supplement them by direct observation of feeding behavior and plant preferences of the few species of herbivorous fishes in the West Indies. STRASBURG \& MARR (1961) have made extensive studies of the feeding behavior of pelagic fishes from ship and raft underwater chambers. Such studies are of pragmatic importance in a fishery that uses hook and line methods.

In our studies of coral reef fishes we have recognized ten major feeding categories. While there may be some food overlap (for example, a fish that is primarily a browser feeding on parts of organisms may occasionally ingest a whole organism), these categories are generally distinct enough so that competition between members of different categories is minimal.

The number of species in each category for the three communities is given in Table 2. A large number of species are listed as pickers, i.e., fishes that consume whole organisms from the substratum. Obviously, this category requires further

Table 2

Number of species in each feeding compartment of three coral reef communities

\begin{tabular}{|lccc|}
\hline Feeding categories & Tektite & FLARE & Bimini UTV \\
\hline Midwater planktivores & 7 & 4 & 5 \\
Benthic planktivores & 9 & 4 & 4 \\
Midwater predators & 1 & 1 & 3 \\
Supra-benthic predators & 5 & 1 & 3 \\
Benthic predators & 11 & 8 & 18 \\
Sandsifters & 4 & 2 & 7 \\
Scrapers & 6 & 4 & 9 \\
Browsers & 3 & 9 & 6 \\
Pickers & 26 & 9 & 34 \\
Parasite pickers & 1 & - & - \\
Obligate sponge dwellers & 2 & - & - \\
\hline Total & 75 & 42 & 89 \\
\hline
\end{tabular}


refinement but at present we do not have enough data to make more precise distinctions or to be certain that each species is assigned to the correct category.

\section{DISCUSSION}

\section{Analysis of resource sharing in coral reef $f$ ish communities}

As a working hypothesis we have assumed that long-term community stability can only be realized when the component species are specialized and adapted so as to permit them to share the available resources in such a way as to minimize direct competition. Our analyses of community structure have therefore been directed at identifying the specific adaptations of form and behavior that permit numerous species to coexist side by side in the same patch of habitat. Although it is a formidable task to analyze the relationships of a large number of species simultaneously, it is relatively simple to separate them into general categories and then to further restrict the categories by considering each aspect of resource sharing in turn.

Our long-term UTV observations have substantiated the general impression of stability. Of the 22 benthic resident species that were observed through the television, 18 or $82 \%$ were seen during every observation period over a span of 15 months. These residents constitute the competitive climate with which nomads must contend in order to utilize the local habitat. Nomads were not as consistently present, in fact only $12 \%$ were present during all of the observation periods. We believe that there is relatively little competition between nomads and residents. Although members of both groups utilize some of the same abundant resources, the nomads can move away in search of scarce items. Thus, we are justified in considering each group separately.

Our next step has been to classify the species of fishes in each of these categories according to their feeding habits. As discussed above, we have tried to use a system that is general enough so that there is very little overlap. A fish that sifts sand for interstitial invertebrates, for example, is unlikely to be a serious competitor of a midwater plankton cropper or of browsers that nibble part of attached sponges.

Within each feeding compartment then, we can consider finer divisions according to activity cycles, specific hunting areas, and eventually preference for certain sizes of prey or for individual prey species.

Such analysis can be continued until we finally are able to specify in a precise way exactly how each species is able to maintain itself in the community by avoiding competition with other species.

At this point we will be able to correlate population levels with physical and chemical parameters, with a view to constructing testable quantitative models. For example, careful observation has revealed that each species of Apogon requires a specific type of shelter site - shaded caves, open tunnels, simple ledges. A measure of the amount of each type of space will then serve as an indication of the carrying capacity of that particular patch of environment. 
At the present time we have only scratched the surface. There is no coral reef fish community that is sufficiently well known to permit the formulation of a meaningful model and indeed we have only begun to accumulate the basic census, behavioral, and life history data that will be needed. Nevertheless, it is clear that we now have the means to gather the necessary data.

Our most pressing need at this time is for longer term studies made by a combination of observation and monitoring techniques. Results from short missions have served to suggest many important lines of investigation and have pointed out areas where additional data collected throughout several annual cycles are critically needed.

Direct observations underwater, especially those involving rebreather gear and saturated diving, are costly in terms of equipment and manpower and often entail a degree of risk to personnel. For these reasons it is desirable that the data to be collected and the approaches to be used be planned well in advance. While the practice of in situ direct observation is relatively new and nearly any observations are useful, especial care should be taken to be sure that diving is not used for collecting data that could be gotten from the surface as well. Preparations should include provision for changing the direction of the research should the original goals prove untenable. One should also be prepared to take advantage of unusual conditions that may occur and to use time to the best advantage by taking data that may not have been in the original plan.

In coral reef fish communities we are dealing with small species, many of which have home ranges small enough to be observed by divers. These fishes commonly have conspicuous morphological and behavioral specializations that remain to be interpreted and it is here that direct observations have the greatest potential for discovering new principles. Nevertheless, there is no reason to believe that any of the findings will be unique to coral reef fishes.

Coral reefs are also some of the least disturbed environments remaining on earth and can well serve as living laboratories which can be used for the investigation of phenomena that apply to all living communities.

\section{SUMMARY}

1. A full understanding of the community ecology of coral reef fishes must be based on an understanding of how fishes interact to share the available resources of the reef environment.

2. The goal of such studies is the construction of suitable models that can be used to predict the effects of environmental changes. The validity of such predictions is a test of the adequacy of the model.

3. The data on which models can be based are obtained in a combination of three approaches: (a) sampling, (b) laboratory experiments and (c) direct observation.

4. Direct observations can be made by viewing from the surface, by the use of underwater chambers, by submersible vehicles, by underwater television and by diving. 
5. The use of diving techniques is limited by visibility, temperature and depth. Diving time can be extended by saturated diving from an underwater habitat.

6. The critical areas for information about coral reef fish communities are: census, population dynamics, natural history and behavior, space sharing and food sharing.

7. Complex communities can be analyzed by successively categorizing the species according to each of these aspects until the unique niche of each species is defined.

8. The most pressing need in the study of coral reef fish ecology is for continuous monitoring of representative stations throughout complete seasonal cycles.

Acknowledgments. The authors are indebted to the agencies and personnel of project Tektite II who made our introduction to saturated diving not only profitable but pleasant as well. We wish to thank the Manned Undersea Science and Technology Office of the U.S. Department of Commerce for the opportunity to take part in project FLARE and we give our heartfelt thanks to the support divers and to the crew of the Research Vessel LULU for their cheerful and competent help. Our studies with the underwater television at The Lerner Marine Laboratory were financed by ONR Contract 552(07), R. M. MATHEwson, principal investigator.

\section{LITERATURE CITED}

BARDACH, J. E., 1959. The summer standing crop of fish on a shallow Bermuda reef. Limnol. Oceanogr. 4, 77-85.

BöHLKe, J. E. \& Chaplin, C. C. G., 1968. Fishes of the Bahamas and adjacent tropical waters. Livingston, Wynnewood, Pa., 771 pp.

Brock, V., 1954. A preliminary report on a method of estimating reef fish populations. J. Wildl. Mgmt 18, 297-308.

Collette, B. B. \& Talbot, F. H., 1972. Activity patterns of coral reef fishes with emphasis on nocturnal-diurnal changeover. Los Ang. County nat. Hist. Mus. Sci. Bull. 14, 98-124.

Courtenay, W. R., 1967. Atlantic fishes of the genus Rypticus (Grammistidae). Proc. Acad. nat. Sci., Philad. 119, 241-293.

EARLE, S. A., 1972. The influence of herbivores on the marine plants of Great Lameshur Bay, with an annotated list of plants. Los Ang. County nat. Hist. Mus. Sci. Bull, 14, 17-44.

Hiatt, R. W. \& Strasburg, D. W., 1960. Ecological relationships of the fish fauna on coral reefs of the Marshall Islands. Ecol. Monogr. 30, 65-127.

High, W. L. \& BeARdsLey, A. J., 1971. Observation of fish behavior in relation to fish pots. In: Scientists in the Sea. Ed. by J. W. Mrletr, J. G. VAN Der walker \& R. A. Waller, U.S. Dpt. Int., Washington, D. C.

Honson, E. S., 1968. Predatory behavior of some shore fishes in the Gulf of California. Res. Rep. U.S. Fish. Wildl. Serv. 73, 1-92.

Lrvingston, R. J., 1971. Circadian rhythms in the respiration of eight species of cardinal fishes (Pisces: Apogonidae): comparative analysis and adaptive significance. Mar. Biol. 9, 253-266.

Munro, J. L., Reeson, P. H. \& Gaut, V. C., 1971. Dynamic factors affecting the performance of the Antillean fish trap. Proc. Gulf Caribb. Fish. Inst. 23, 184-194.

RANDALL, J. E., 1965. Grazing effect on the sea grasses by herbivorous reef fishes in the West Indies. Ecology 46, 255-260.

- 1967. Food habits of reef fishes of the West Indies. Stud. trop. Oceanogr. 5, 665-847.

SMTH, C. L., 1973. Small rotenone stations: a tool for studying coral reef fish communities. Am. Mus. Novit. 2512, 1-21.

- \& Tyler, J. C., 1972. Space resource sharing in a coral reef fish community. Los Ang. County nat. Hist. Mus. Sci. Bull. 14, 125-170. 
- 1974. Population ecology of a Bahamian supra-benthic shore fish assemblage. Am. Mus. Novit. (In press).

Starck, W. A. \& Davis, W. P., 1966. Night habits of fishes of Alligator Reef, Florida. Ichthyologica 38, 313-356.

Strasburg, D. W. \& MarR, J. C., 1961. Banded color phases of two pelagic fishes, Coryphaena hippurus and Katsuwonus pelamis. Copeia 1961, 226-228.

First author's address: Dr. C. L. SMiTH

Department of Ichthyology

The American Museum of Natural History

New York, N. Y. 10024

USA 